\title{
Mast Cell Degranulation Increases Mouse Mast Cell Protease 4-Dependent Vasopressor Responses to Big Endothelin-1 But Not Angiotensin [S
}

\author{
Laurence Vincent, Catherine Lapointe, Modou Lo, Hugo Gagnon, Gunnar Pejler, \\ Shinji Takai, Robert Day, and Pedro D'Orléans-Juste
}

Department of Pharmacology and Physiology, Faculté de Médecine et des Sciences de la Santé, Université de Sherbrooke, Sherbrooke, Quebec, Canada (L.V., C.L., M.L., P.D.-J.); PhenoSwitch Bioscience Inc., Sherbrooke, Quebec, Canada (H.G.); Department of Medical Biochemistry and Microbiology, Uppsala University, Uppsala, Sweden (G.P.); Department of Innovative Medicine, Osaka Medical College, Osaka, Japan (S.T.); and Department of Surgery, Division of Urology, Université de Sherbrooke, Sherbrooke, Quebec, Canada (R.D.)

Received September 7, 2020; accepted November 2, 2020

\begin{abstract}
Mouse mast cell protease 4 (mMCP-4), the murine functional analog to the human chymase, is a serine protease synthesized and stored in mast cell secretory granules. Our previous studies reported physiologic and pathologic roles for mMCP-4 in the maturation and synthesis of the vasoactive peptide endothelin-1 (ET-1) from its precursor, big ET-1. The aim of this study was to investigate the impact of mast cell degranulation or stabilization on mMCP-4-dependent pressor responses after the administration of big ET-1 or angiotensin I (Ang I). In anesthetized mice, mast cell degranulation induced by compound $48 / 80$ (C48/80) or stabilization by cromolyn enhanced or repressed, respectively, the dose-dependent vasopressor responses to big ET-1 in wildtype (WT) mice but not in mMCP-4 knockout mice in a chymase inhibitor (TY-51469)-sensitive fashion. In addition, mMCP4-dependent hydrolysis of the fluorogenic substrate Suc-LeuLeu-Val-Tyr-7-amino-4-methylcoumarin was depleted or enhanced in peritoneal mast cells isolated from mice pretreated
\end{abstract}

with C48/80 or cromolyn, respectively. Furthermore, C48/80 or cromolyn markedly increased or abolished, respectively, ET-1 (1-31) conversion from exogenous big ET-1 in WT mice peritoneal fluid-isolated mast cells, in vitro. Finally, the vasopressor responses to Ang I were unaffected by mast cell activation or stabilization, whereas those induced by the angiotensinconverting enzyme-resistant Ang I analog, [Pro ${ }^{11}$, D-Ala $\left.{ }^{12}\right]$ Ang I, were potentiated by $\mathrm{C} 48 / 80$. Altogether, the present study shows that mast cell activation enhances the mMCP-4-dependent vasoactive properties of big ET-1 but not Ang I in the mouse model.

\section{SIGNIFICANCE STATEMENT}

The current work demonstrates a significant role for mast cell stability in the cardiovascular pharmacology of big endothelin-1 but not angiotensin I in the murine systemic circulation.

\section{Introduction}

Upon activation, mast cells undergo a biphasic secretory response involving the rapid release of prestored vasoactive mediators followed by subsequent release of de novo synthesized products, significantly modulating several physiologic and pathologic pathways (Blank, 2011). Secretion of the serine protease chymase, a major component of the mast cell secretory granules, is notably involved in the maturation of vasoactive factors such as angiotensin II (Ang II) and

This project was financially supported by the Canadian Institutes for Health Research (MOP-57883) and le Réseau Québecois de Recherche sur le Médicament (Fonds de Recherche Santé, Québec). P.D.-J. is the recipient of a Joseph C. Edwards Cardiology Chair. C.L. is the recipient of a doctorate studentship from the Université de Sherbrooke.

https://doi.org/10.1124/jpet.120.000325.

S This article has supplemental material available at jpet.aspetjournals.org. endothelin-1 (ET-1) (Nakano et al., 1997; Fleming, 2006), both acting in the regulation of the vascular flow and hemodynamic balance (Rossi et al., 1999).

Comparative studies in human, hamster, rat, rabbit, dog, pig, and marmoset tissues reported remarkable variations in the Ang II-forming pathways among several organs in vitro, suggesting that the chymase contribution to local Ang II generation could be species-dependent (Balcells et al., 1997; Akasu et al., 1998; Kunori et al., 2005). By adopting an in vitro mouse model, it was shown that, under physiologic conditions, angiotensin-converting enzyme (ACE) is the major Ang IIforming dipeptidyl-carboxypeptidase (Company et al., 2011). Ang II can, however, under inflammatory conditions, also be generated via mast cell activation by release of the extravascular mouse mast cell protease 4 (mMCP-4) (Company et al., 2011), the closest mouse analog to human chymase (Pejler et al., 2010). Notably, though, whether mast cell activation

ABBREVIATIONS: ACE, angiotensin-converting enzyme; AMC, 7-amino-4-methylcoumarin; Ang I, angiotensin I; Ang II, angiotensin II; BSA, bovine serum albumin; C48/80, compound 48/80; ECE, endothelin-converting enzyme; ET-1, endothelin-1; HR, heart rate; KO, knockout; MAP, mean arterial pressure; mMCP-4, mouse mast cell protease 4; NEP, neprilysin; rmMCP-4, recombinant mMCP-4; WT, wild type. 
and secretion of mMCP-4 can modulate the response of the cardiovascular system to angiotensin I (Ang I) in vivo remains to be determined.

The endothelin-converting enzyme (ECE) is located on endothelial cells membrane but also on a wide variety of cell types such as vascular smooth muscle cells, macrophages, and neurons (Davenport et al., 2016). Such cells produce ET-1 through ECE-mediated conversion of big ET-1 (McMahon et al., 1991; Xu et al., 1994). An alternate pathway of ET-1 generation involves mast cell chymase, through the production of an inactive intermediate, ET-1 (1-31), as shown in human tracheal smooth muscle cells (Nakano et al., 1997). ET$1(1-31)$ is subsequently cleaved by the neprilysin (NEP) to form the vasoactive peptide ET-1 (1-21), which is a prerequisite to exert its pressor properties in vivo (Fecteau et al., 2005). We have previously shown a $40 \%$ reduction in the pressor responses induced by the administration of big ET-1 in mice genetically deficient for mMCP-4 (mMCP-4 KO) (Tchougounova et al., 2003), demonstrating a dynamic role for chymase in the generation of ET-1 in vivo (Houde et al., 2013). Although mMCP-4 metabolizes big ET-1 in vivo and Ang I in vitro (Fecteau et al., 2005; Fleming, 2006), the impact of acute mast cell activation or stabilization on the hydrolytic properties of mMCP-4 in vivo remains uninvestigated. We suggest that mast cell degranulation enhances mMCP-4-dependent cardiovascular responses to big ET-1 in the mouse model in vivo.

This study therefore investigated the influence of mast cell degranulation on the chymase-dependent pressor responses to big ET-1 or Ang I in wild-type (WT) or mMCP-4 KO mice. These agonists were tested in mice treated with the mast cell degranulating agent compound 48/80 (C48/80) (IrmanFlorjanc and Erjavec, 1983) or the mast cell stabilizer cromolyn (Samoszuk and Corwin, 2003) and when applicable with the chymase inhibitor TY-51469 (Koide et al., 2003). Finally, the contribution of degranulated mMCP-4 on the pressor responses to $\left[\mathrm{Pro}^{11}, \mathrm{D}-\mathrm{Ala}^{12}\right]$ Ang I, an ACE-resistant analog (McDonald et al., 2001) was also investigated in vivo.

Our study shows that modulation of mast cell activation significantly impacts the hemodynamic responses to big ET-1 but not Ang I.

\section{Methods}

Animals. C57Bl/6 mice genitors were purchased from Charles River Canada (Montreal, QC, Canada) and housed in our facilities. Genitor mMCP-4 KO mice were provided by Dr Gunnar Pejler (Uppsala University, Sweden) and bred in our facility. All animals (male mice, 8-12 weeks old) were kept at constant room temperature $\left(23^{\circ} \mathrm{C}\right)$ and humidity $(78 \%)$ under a controlled 12-hour light/dark cycle, with standard chow and tap water ad libitum. Animal care and experimentations were approved by the Ethics Committee on Animal Research of the University of Sherbrooke following the Canadian Council on Animal Care guidelines and the Guide for the Care and Use of Laboratory Animals of the US National Institutes of Health.

Mice were anesthetized by the intramuscular administration of ketamine/xylazine $(87 / 13 \mathrm{mg} / \mathrm{kg})$. The intraperitoneal administration of vehicle, C48/80 (1 mg/kg) or cromolyn $(50 \mathrm{mg} / \mathrm{kg}), 5$ or 30 minutes, respectively, prior to further experimentation, was performed (Röhlich et al., 1971; Skedinger et al., 1987; Tariq et al., 2006).

Hemodynamic Monitoring in Anesthetized Mice. The method was performed as previously described (Houde et al., 2013). Anesthetized mice were cannulated with a polyethylene catheter via the left jugular vein for intravenous administration and the right carotid artery for hemodynamic recordings using the Blood Pressure Analyzer 200A (Digi-Med, Louisville, KY). After the surgery, the mice were allowed a 15-minute stabilization period before the intravenous injection of either big ET-1 (Phoenix Pharmaceuticals Inc., Burlingame, CA), ET-1 (1-31) (Peptide Institute, Osaka, Japan), ET-1 (Enzo Life Sciences Inc. Farmingdale, NY), Ang I (TOCRIS Bioscience, Ellisville, MO), or [Pro ${ }^{11}$, D-Ala ${ }^{12}$ ] Ang I (American Peptide Company; Sunnyvale, CA) with doses ranging from $0.001 \mathrm{nmol} / \mathrm{kg}$ to $10 \mathrm{nmol} / \mathrm{kg}$ (D'Orléans-Juste et al., 2008). Each mouse was administered a unique dose, and blood pressure parameters were continuously monitored for a maximum of 20 minutes before the mice were sacrificed by cervical dislocation. All data were analyzed using the DMSI-400 System Integrator software (System Integrator; Digi-Med). Blood pressure variations $(\Delta)$ obtained after the injection of each vasopressor were calculated as the difference between blood pressure increases postinjection and basal pressure recorded prior to administration of each agent. Recording of heart rate (HR) was initiated at the time of agonist administration. In another series of experiments, the specific chymase inhibitor TY-51469 (10 mg/kg) (Toa Eiyo limited, Osaka, Japan) was administered intravenously 20 minutes before drug administration.

Peritoneal Mast Cells Isolation. Mast cells from the peritoneal cavity were isolated from vehicle, C48/80 or cromolyn pretreated mice (as described above) and used for measurement of chymase activity as previously reported (Semaan et al., 2015). Mice anesthetized with ketamine/xylazine $(87 / 13 \mathrm{mg} / \mathrm{kg}$, intramuscular) were injected with $5 \mathrm{ml}$ of isolation buffer (PBS pH 7.4 containing $1 \mathrm{mg} / \mathrm{ml}$ of bovine serum albumin (BSA) and $0.5 \mathrm{mg} / \mathrm{ml}$ of heparin) in the peritoneal cavity. The peritoneal fluids were collected after a 1-minute abdominal massage and centrifuged at $200 \mathrm{~g}$ for 5 minutes. Pellets were suspended in $1 \mathrm{ml}$ of RPMI-1640 medium containing $2 \mathrm{mM}$ of L-glutamine, $100 \mathrm{U} / \mathrm{ml}$ of penicillin, and $1 \mathrm{mg} / \mathrm{ml}$ of $\mathrm{BSA}$ and subsequently incubated for 1 hour at $37^{\circ} \mathrm{C}$ in tissue culture dishes $35 \times 10 \mathrm{~mm}$ to sediment and allow adherence to the plastic surface of the dish the macrophages and leukocytes, thus permetting a purification of the mast cells. RPMI-1640 medium and nonadherent cells were collected and centrifuged at $200 g$ for 5 minutes. Pellets were suspended in $1 \mathrm{ml}$ of isolation buffer, and cells were counted using a hemocytometer (zoom in to $40 \times$ magnification) according to the Moore and James method with toluidine blue (0.038\%) (Moore and James, 1953). A final centrifugation was performed at $200 \mathrm{~g}$ for 5 minutes, and pellets were suspended in PBS ( $\mathrm{pH} 8)$ at a concentration of $1 \times 10^{4}$ cells $/ \mu$ l.

Activation of the Recombinant Enzymes. Recombinant mMCP4 was expressed in S2 Drosophila cells and purified as previously described (Semaan et al., 2015). The recombinant enzymes were thawed and diluted to a concentration of $20 \mu \mathrm{g} / \mathrm{ml}$ in maturation buffer $(50 \mathrm{mM}$ 2-(N-morpholino)ethanesulfonic acid (MES), $1 \mathrm{mg} / \mathrm{ml} \mathrm{BSA}, \mathrm{pH} 5.5$ ). Active murine cathepsin C (R\&D Systems, Minneapolis, MN) was diluted to $20 \mu \mathrm{g} / \mathrm{ml}$ in cathepsin $\mathrm{C}$ buffer (50 mM MES, $50 \mathrm{mM} \mathrm{NaCl}$, $5 \mathrm{mM}$ Dithiothreitol (DTT), $\mathrm{pH}$ 5.5). Activation was performed by adding equal volumes of recombinant chymase and cathepsin $\mathrm{C}$, adding $50 \mu \mathrm{g} / \mathrm{ml}$ heparin, and incubating 1 hour at room temperature. mMCP-4 activation was stopped with $N$-Ethylmaleimide (NEM) (3 mM) and diluted with assay buffer ( $20 \mathrm{mM}$ Tris, $200 \mu \mathrm{M} \mathrm{KCl}, 0.02 \%$ Triton X-100, $\mathrm{pH} 9.0$ ) to bring the recombinant enzyme concentration to 2 or $5 \mu \mathrm{g} / \mathrm{ml}$, and 5 minutes was allowed to completely stop the cathepsin $\mathrm{C}-$ dependent reaction.

Measurement of Chymase Enzymatic Activity. Activated recombinant mMCP-4 (rmMCP-4) at concentrations of $30.85 \mathrm{nM}$ (100 ng/well) and $154.32 \mathrm{nM}$ (500 ng/well), in absence or presence of $\mathrm{C} 48 / 80(12 \mu \mathrm{M})$, cromolyn $(600 \mu \mathrm{M})$ or TY-51469 $(10 \mu \mathrm{M})$, or mast cells $\left(1 \times 10^{5}\right.$ cells $)$, were incubated in 96 well plates with the fluorogenic substrate, Suc-Leu-Leu-Val-Tyr-7-amino-4-methylcoumarin (AMC) $(10 \mu \mathrm{M})$ (Peptide Institute inc., Osaka, Japan). The fluorescence of the released AMC molecule, as chymotrypsin-like activity, was then measured in duplicate with an Infinite M1000 spectrophotometer (Tecan Group Ltd., Männerdorf, Swiss) with $\lambda_{\mathrm{ex}}=370 \mathrm{~nm}$ and $\lambda_{\mathrm{em}}=$ $460 \mathrm{~nm}$, at $37^{\circ} \mathrm{C}$ for up to 20 minutes. 
Mast Cell-Specific Conversion of Big ET-1 to ET-1 (1-31) In Vitro. Big ET-1 $(15 \mu \mathrm{M})$ was incubated with $1 \times 10^{5}$ mast cells. Thiorphan $(1 \mu \mathrm{M})$, an NEP inhibitor, was added to the reaction to block conversion of ET-1 (1-31) to ET-1. C48/80 (1 $\mu \mathrm{M})$ or cromolyn $(20$ $\mu \mathrm{M})$ was added to the medium and incubated for 20 minutes at $37^{\circ} \mathrm{C}$. Formic acid (4\%) was added to lower the $\mathrm{pH}$ and to completely stop the enzymatic reaction.

Peptide samples (200 $\mu$ l per tube) were analyzed via liquid chromatography-tandem mass spectrometry analysis by PhenoSwitch Bioscience Inc. Each sample was loaded on Strata-X polymeric reversed-phase columns. Peptides were eluted twice with $350 \mu \mathrm{l}$ $75 \%$ acetonitrile, $2 \%$ formic acid. Eluates were dried, samples were then suspended in $50 \mu \mathrm{l}$ of $\mathrm{H}_{2} \mathrm{O}$ with $2 \%$ formic acid, and $5 \mu \mathrm{l}$ was injected on a Halo peptide $\mathrm{C} 1850 \times 0.5 \mathrm{~mm}$ column eluted with water, $3 \%$ DMSO, $0.2 \%$ formic acid (mobile phase A) and acetonitrile, $3 \% \mathrm{DMSO}, 0.2 \%$ formic acid (mobile phase B). The flow rate was $25 \mu \mathrm{l} / \mathrm{min}$ for the 2.5-minute duration, and gradients started at $10 \%$ mobile phase B. ET-1, ET-1 (1-31), and big ET-1 were monitored by product ion acquisition on a TTOF5600 from AbSciex.

Statistical Analysis. All quantitative results are presented as means \pm S.E.M. All graphical and statistical analysis were conducted on GraphPad Prism 8 software (GraphPad Software, La Jolla, CA). Statistical significance was determined with Student's $t$ test for comparisons of two samples or ANOVA with Dunnett's multiple comparison tests for three or more sample sets. Statistical significance was reached when the $P$ value was below 0.05 .

\section{Results}

No Differences in Basal Hemodynamic Parameters in WT and mMCP-4 KO Mice After the Intraperitoneal Administration of C48/80 or Cromolyn. Prior to drug injections, the basal hemodynamic parameters were measured in anesthetized mice treated with either vehicle, C48/80, or cromolyn. Mean, systolic and diastolic arterial pressure, HR, and arterial pulse pressure were similar in both groups regardless of the pharmacological agent administered (Supplemental Table 1).

Interfering with Mast Cell Stability Modulates the mMCP-4-Dependent Hemodynamic Responses to Big ET-1. The dose-dependent increases in mean arterial pressure

$$
\text { -. Vehicle } \rightarrow \mathrm{C} 48 / 80 \neq \text { Cromolyn }
$$

A

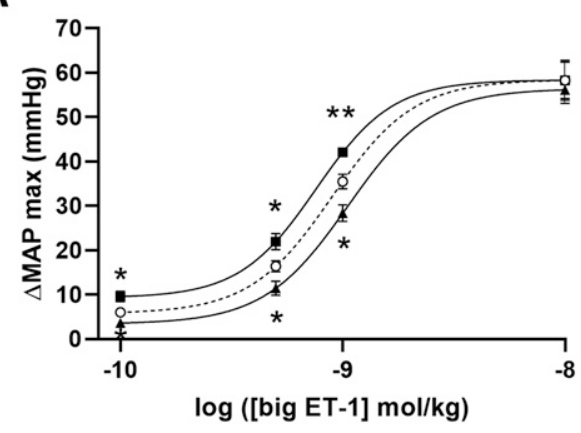

C
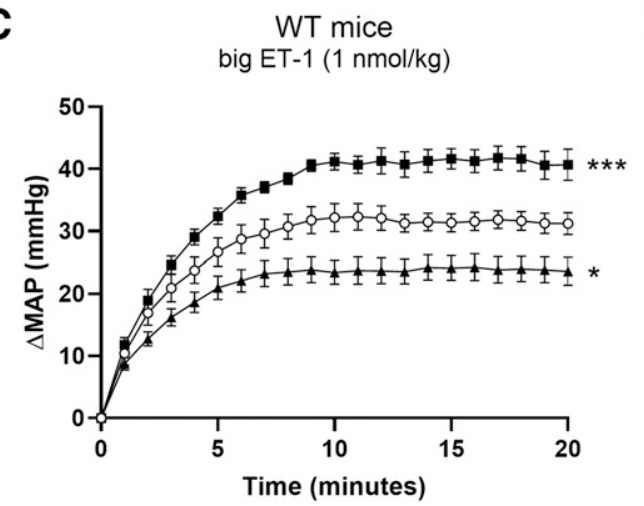

E

WT mice big ET-1 (1 nmol/kg)

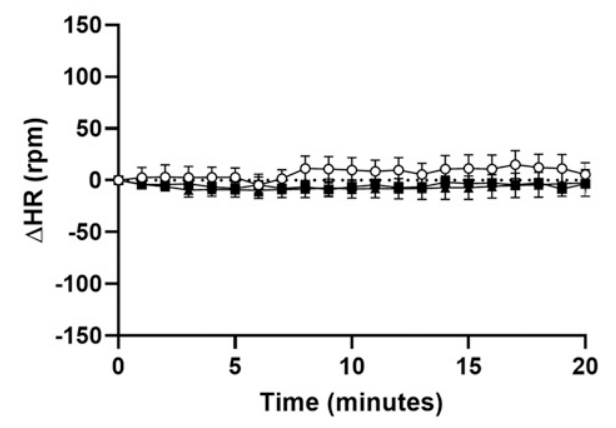

B

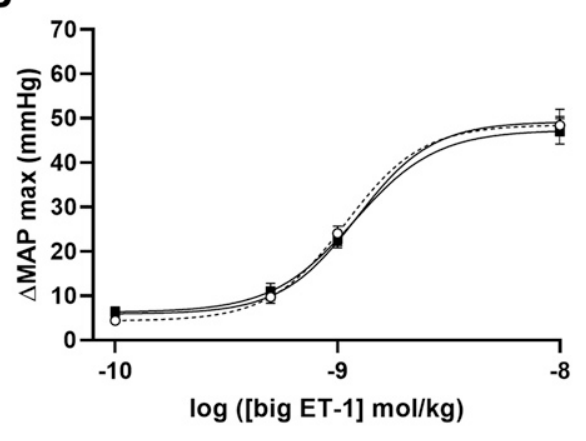

D

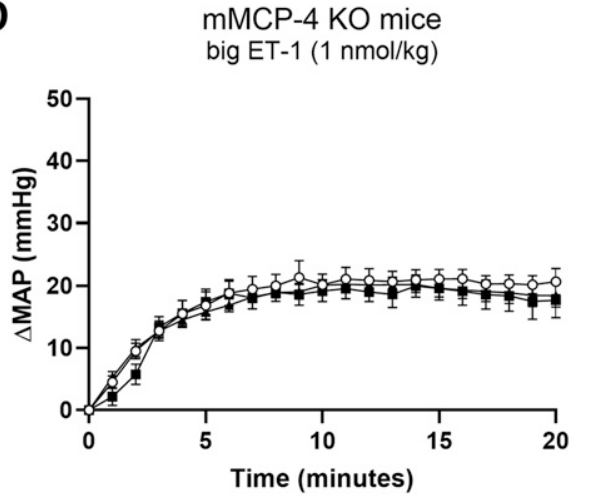

$\mathbf{F}$

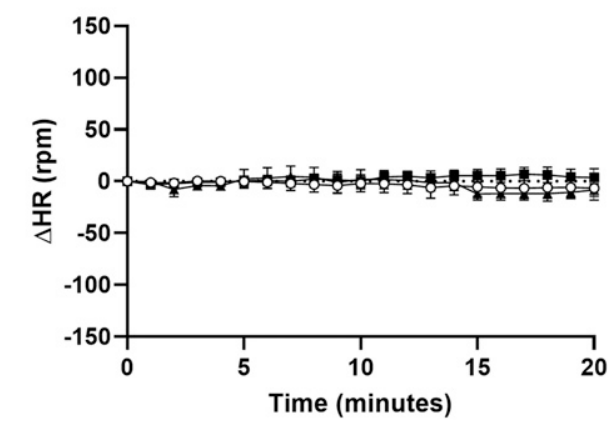

Fig. 1. Maximal variation in MAP after intravenous administration of big ET-1 in WT (A) and mMCP-4 KO (B) mice pretreated with either vehicle, $\mathrm{C} 48 / 80$ or cromolyn; time course of the $\triangle \mathrm{MAP}$ in response to intravenous administration of a single dose of big ET-1 $(1 \mathrm{nmol} / \mathrm{kg})$ in WT (C) and mMCP-4 KO (D) mice pretreated with the above-mentioned agents, and their respective $\mathrm{HR}$ ( $\mathrm{E}$ and $\mathrm{F}$ ). Each point corresponds to the mean \pm S.E.M. of the MAP increase $(n=6-10) . * P<0.05$; $* * P<0.01 ; * * * P<0.001 \mathrm{vs}$. WT + vehicle by one-way ANOVA with Dunnett's multiple comparison test. 


\section{A big ET-1 $(1 \mathrm{nmol} / \mathrm{kg})$}

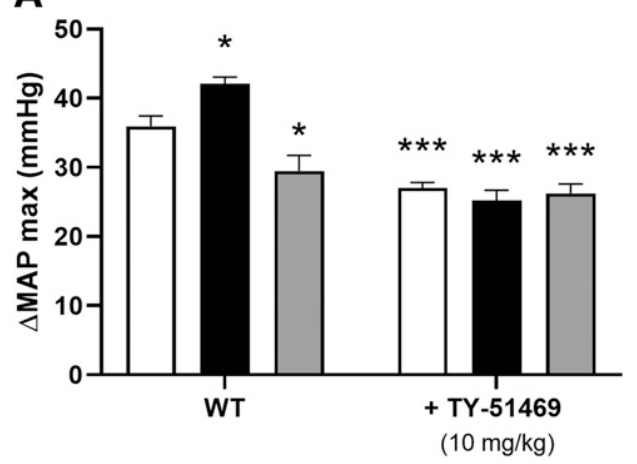

B

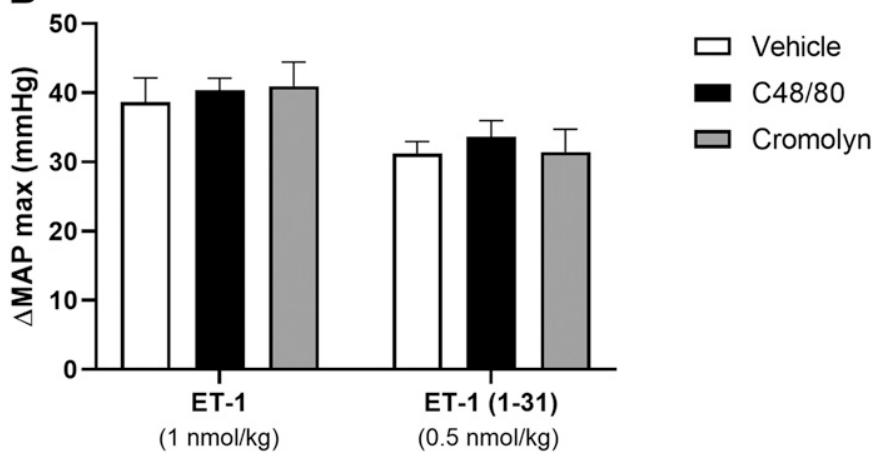

Fig. 2. (A) Maximal variation in MAP in response to big ET-1 (1 nmol/kg) in WT mice pretreated intravenously with vehicle or TY-51469 $(10 \mathrm{mg} / \mathrm{kg})$. (B) Maximal $\triangle$ MAP after intravenous administration of ET-1 (1-31) $(1 \mathrm{nmol} / \mathrm{kg})$ and ET-1 $(0.5 \mathrm{nmol} / \mathrm{kg})$ in WT mice. Each bar corresponds to the mean \pm S.E.M. of the MAP increase $(n=5-9)$. $* P<0.05 ; * * * P<0.001$ vs. WT + vehicle by one-way ANOVA with Dunnett's multiple comparison test.

(MAP) after bolus administrations (intravenous) of big ET-1 were compared in WT and mMCP-4 KO mice, treated intraperitoneally with $\mathrm{C} 48 / 80(1 \mathrm{mg} / \mathrm{kg})$ or cromolyn $(50 \mathrm{mg} / \mathrm{kg})$. $\mathrm{C} 48 / 80$ potentiated the maximal increases of the MAP induced by exogenous big ET-1 at doses ranging from 0.01 to $1 \mathrm{nmol} / \mathrm{kg}$ $(P<0.05)$, with no variations of $\mathrm{HR}$ at all doses tested. In contrast, at the same doses, pressor responses to big ET-1 were markedly reduced in cromolyn-treated WT $(P<0.05)$ but not in mMCP-4 KO mice (Fig. 1, A and B). Figure 1, C and D, shows that the potentiating or repressing effects of C48/80 or cromolyn, respectively, occur throughout the sustained pressor responses to big ET-1 in WT mice. Finally, no effects of C48/ 80 , cromolyn or mMCP-4 deficiency on $\mathrm{HR}$ in response to big ET-1 were observed (Fig. 1, E and F).

Interfering with Mast Cell Stability Does Not Influence the Hemodynamic Responses to Big ET-1 Metabolites ET-1 (1-31) or ET-1. A specific chymase inhibitor, TY-51469 (10 mg/kg, intravenous), suppressed the mMCP-4 contribution to the pressor responses to big ET-1 in WT mice $(P<0.001)$, regardless of induction of mast cell degranulation or stabilization (Fig. 2A). ET-1 (1-31) $(1 \mathrm{nmol} / \mathrm{kg})$ and ET-1 (0.5 nmol/kg) induced similar hemodynamics in WT mice treated with vehicle, C48/80, or cromolyn (Fig. 2B). Thus, mast cell stability plays no significant role in the vasoactive effects of the latter two metabolites.

C48/80 and Cromolyn Increase or Abolish, Respectively, Mast Cells Derived mMCP-4-Dependent Conversion of Big ET-1 to ET-1 (1-31). In a first series of specificity experiments, concentration-dependent chymase activity of recombinant mMCP-4 was assessed (Supplemental Fig. 1). Furthermore, the latter serine protease activity was not modified by C48/80 or cromolyn yet abolished by TY-51469 (Fig. 3A).

The hydrolysis of the fluorogenic substrate was subsequently measured in peritoneal fluid-isolated mast cells from
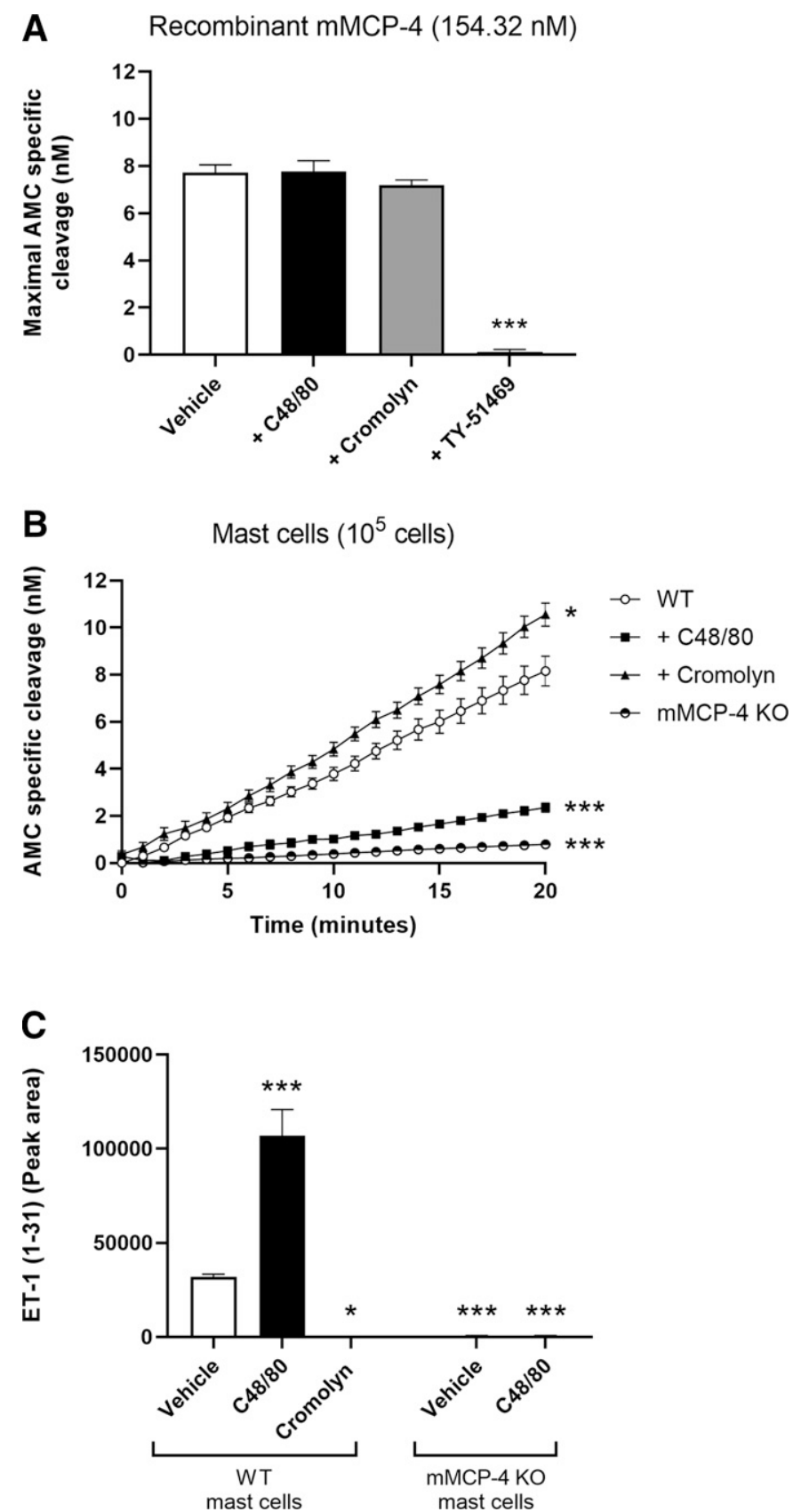

Fig. 3. (A) Quantification of the specific cleavage of the fluorogenic substrate Suc-Leu-Leu-Val-Tyr-AMC by rmMCP-4 (154.32 $\mathrm{nM})$ in the presence of vehicle, C48/80 (12 $\mu \mathrm{M})$, cromolyn $(600 \mu \mathrm{M})$, or TY-51469 (10 $\mu \mathrm{M})(n=6)$. (B) Quantification of the specific AMC cleavage of the fluorogenic substrate measured ex vivo in peritoneal fluid-isolated mast cells derived from WT (pretreated with vehicle, C48/80 or cromolyn) or mMCP-4 KO mice $(n=6-10)$. (C) In vitro conversion of big ET-1 into ET-1 (1-31) from intact peritoneal mast cells derived from WT or mMCP-4 KO in presence of vehicle, $\mathrm{C} 48 / 80(1 \mu \mathrm{M})$ or cromolyn $(20 \mu \mathrm{M})$ using mass spectrometry area under the curve arbitrary units $(n=4$ to 5$)$. Each point and bar correspond to the mean \pm S.E.M. ${ }^{*} P<0.05$; $* * * P<0.001$ vs. rmMCP-4 or WT + vehicle by one-way ANOVA with Dunnett's multiple comparison test. 
WT and mMCP-4 KO mice pretreated with either vehicle, C48/ 80 , or cromolyn. Figure 3B shows that WT but not mMCP-4 KO mast cells show hydrolytic activity and that C48/80 markedly reduced $(P<0.001)$ mast cells' chymase-like activity, suggesting a lower content in mMCP-4 post- degranulation. On the other hand, cromolyn produced an increase in hydrolytic activity $(P<0.05)$, suggesting a greater enzyme content in stabilized WT mast cells. We had previously reported that WT mouse peritoneal mast cells possess mMCP-4-dependent hydrolytic activity (Semaan et al., 2015; Desbiens et al., 2019). Worthy of notice, $1 \times 10^{5}$ isolated peritoneal mast cells were equivalent to a concentration of 150 $\mathrm{nM}$ of the recombinant mMCP-4 in terms of chymase-specific hydrolysis.

Finally, C48/80 and cromolyn, respectively, enhanced or abolished the production of ET-1 (1-31) from exogenous big
ET-1 in mast cells isolated from WT mice peritoneal fluid ( $P<$ 0.001 and $P<0.05$, respectively) (Fig. 3C). ET-1 (1-31) generation did not occur in peritoneal mast cells derived from mMCP-4 KO mice $(P<0.001)$ (Fig. 3C).

C48/80 or Cromolyn Do Not Affect Hemodynamic Responses to Ang I in Anesthetized Mice. The absence of mMCP-4-specific contributions in the generation of the potent vasopressor peptide Ang II is shown in Fig. 4. Ang I (0.001-0.5 $\mathrm{nmol} / \mathrm{kg}$ ) administered to either WT or mMCP-4 KO mice elicited similar vasopressor responses (Fig. 4A). Higher doses of Ang I triggered tachycardia in the anesthetized mouse model (data not shown). Figure 4, B and C, shows no effects of $\mathrm{C} 48 / 80$ or cromolyn on duration of the pressor responses to Ang I $(0.01 \mathrm{nmol} / \mathrm{kg})$, either in WT or $\mathrm{mMCP}-4 \mathrm{KO}$ mice. Furthermore, no effects of C48/80, cromolyn or mMCP-4 deficiency on $\mathrm{HR}$ in response to Ang I were detected (Fig. 4, D and E).

A

Ang I

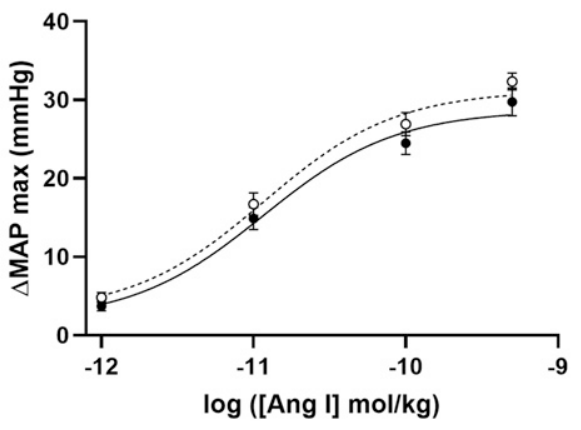

-... WT

- mMCP-4 KO

B
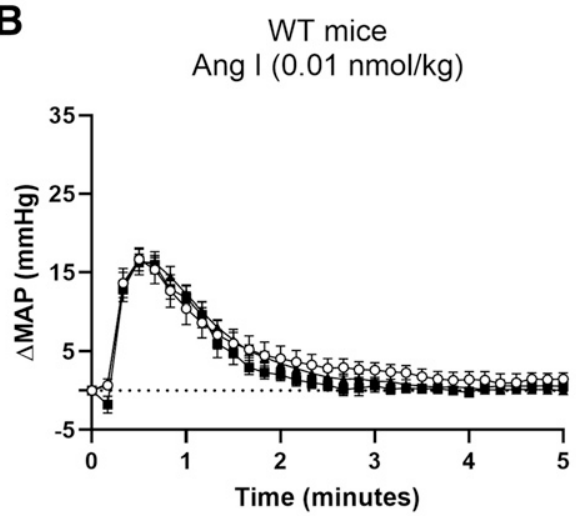

D
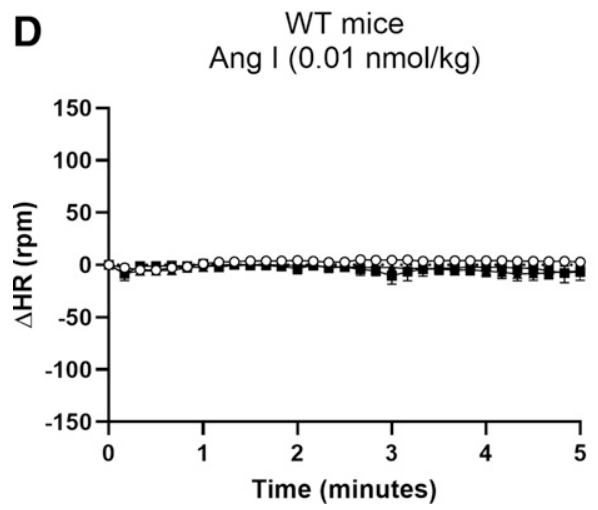

C

mMCP-4 KO mice

Ang I $(0.01 \mathrm{nmol} / \mathrm{kg})$

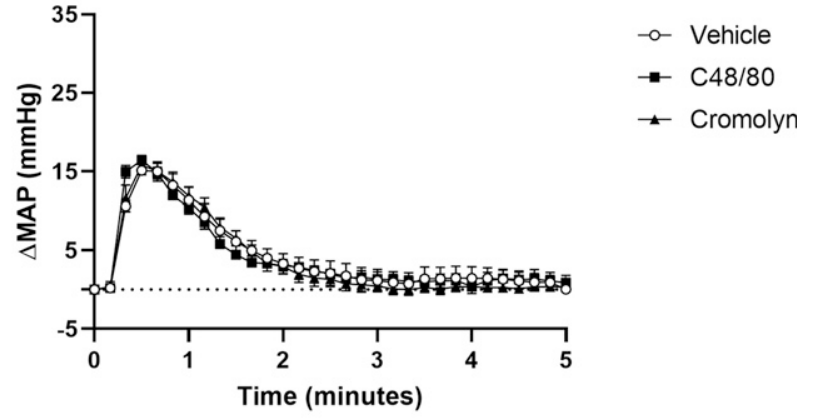

E

mMCP-4 KO mice

Ang I $(0.01 \mathrm{nmol} / \mathrm{kg})$

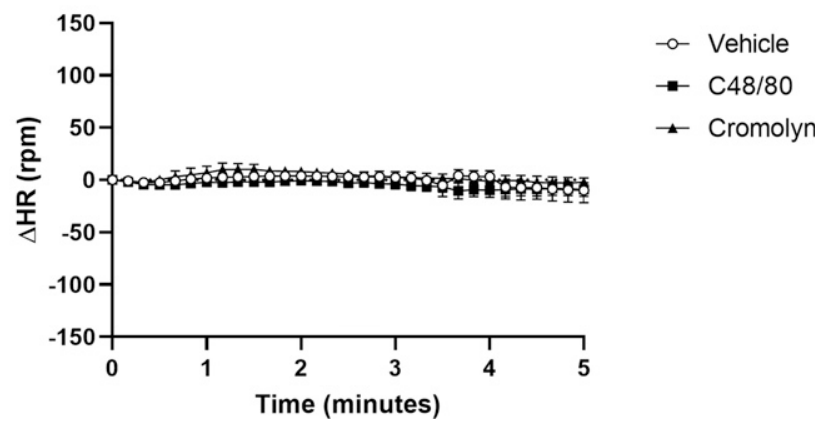

Fig. 4. (A) Maximal variation in MAP after the intravenous administration of Ang I in WT and mMCP-4 KO mice; time course of the variation of the $\triangle$ MAP in response to intravenous administration of Ang I $(0.01 \mathrm{nmol} / \mathrm{kg})$ in WT (B) and mMCP-4 KO mice (C) pretreated with vehicle, C48/80 or cromolyn, and their respective HR (D and E). Each point and bar correspond to the mean \pm S.E.M. of the MAP increase of 6-8 separate experiments. 
Mast Cell Degranulation Modulates the mMCP-4Dependent Hemodynamic Responses to [Pro ${ }^{11}, \mathrm{D}^{-\mathrm{Ala}^{12}}{ }^{12}$ Ang I. In contrast to Ang I, administration of the ACE-resistant analog $\left[\mathrm{Pro}^{11}, \mathrm{D}-\mathrm{Ala}^{12}\right]$ Ang I induced pressor responses with greater amplitude and duration in WT mice when compared to their mMCP-4 KO congeners $(P<0.01)$, unmasking a chymase-dependent contribution in the vasopressor responses to this particular peptide (Fig. 5, A-C), whereas similarly to Ang I, no significant effects on HR were observed with the analog.

In addition, in WT but not mMCP-4 KO mice, C48/80 potentiated by 2.5 -fold $(P=0.001)$ (in terms of amplitude and duration) the pressor responses to $\left[\mathrm{Pro}^{11}, \mathrm{D}^{1} \mathrm{Ala}^{12}\right.$ ] Ang I (Fig. 6, A-C). As positive chronotropic response to the ACE-resistant analog of Ang I was also prompted by $\mathrm{C} 48 / 80$ (Fig. $6 \mathrm{D}$ ) in WT but not in mMCP-4 KO mice (Fig. 6, C and E). Finally, cromolyn did not modify the cardiovascular responses to $\left[\mathrm{Pro}^{11}, \mathrm{D}-\mathrm{Ala}^{12}\right]$ Ang I in either mouse strains.

\section{Discussion}

Our previous studies have demonstrated a contribution of mast cell-secreted mMCP-4 in the ECE-independent production of ET-1 in mice (Fecteau et al., 2005; Simard et al., 2009; Houde et al., 2013). Until the present study, however, it had not been established whether mast cell stability impacts on the mMCP-4-dependent biologic responses to big ET-1 and Ang I in vivo. This study shows that induction of mast cell degranulation by C48/80 increases mMCP-4-dependent responses to exogenous big ET-1. In contrast, the mast cell stabilizer cromolyn reduced the biologic activity and chymase-dependent hydrolysis of big ET-1. Furthermore, mMCP-4 does not significantly contribute to the vasoactive

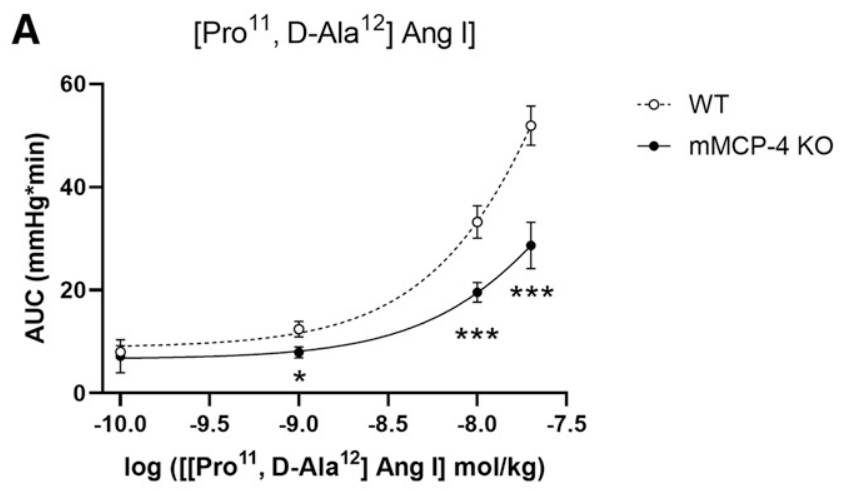

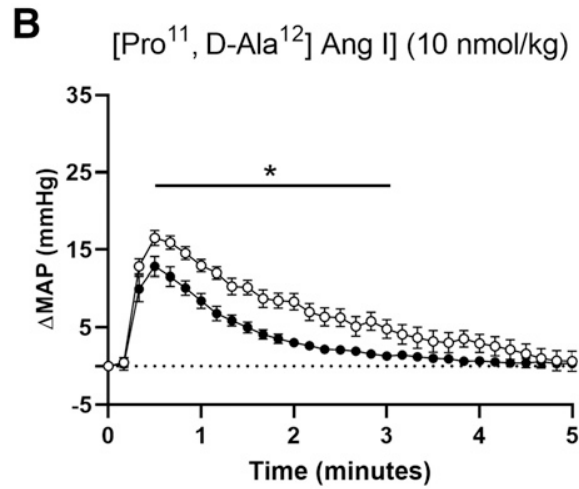

D

$\left[\right.$ Pro $^{11}$, D-Ala $\left.{ }^{12}\right]$ Ang I] $(10 \mathrm{nmol} / \mathrm{kg})$

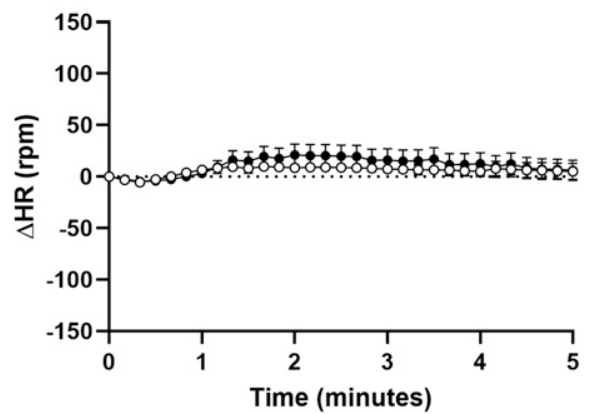

C $\left[\right.$ Pro $^{11}, \mathrm{D}^{-\mathrm{Ala}^{12}}{ }^{2}$ Ang I $](20 \mathrm{nmol} / \mathrm{kg})$
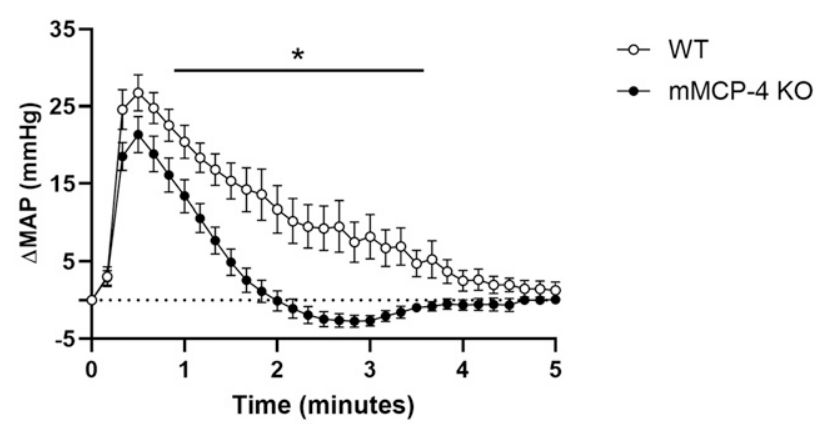

E

[Pro ${ }^{11}, \mathrm{D}-\mathrm{Ala}^{12}$ ] Ang I] $(20 \mathrm{nmol} / \mathrm{kg})$

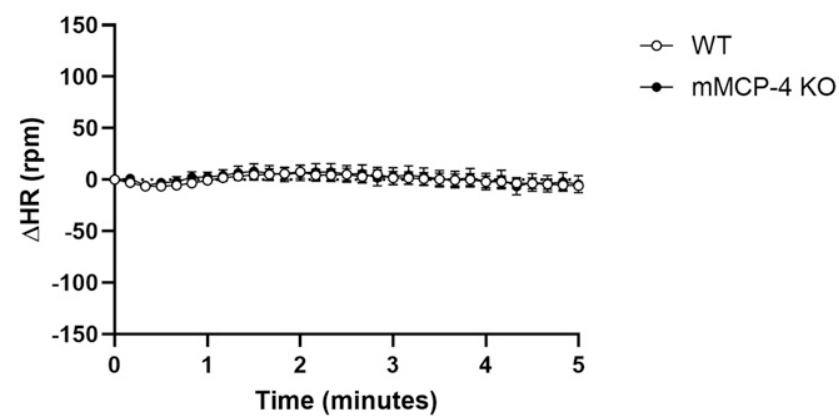

Fig. 5. (A) Dose-response curves [area under the curve (AUC)] of the ACE-resistant analog ([Pro ${ }^{11}$, D-Ala $\left.{ }^{12}\right]$ Ang I) in WT and mMCP-4 KO mice $(n=$ 4-9); time course of maximal variation in MAP in response to intravenous administration of [Pro $\left.{ }^{11}, \mathrm{D}_{-\mathrm{Ala}}{ }^{12}\right] \mathrm{Ang} \mathrm{I}$ [(B) $10 \mathrm{nmol} / \mathrm{kg}(n=8-9)$; (C) 20 $\mathrm{nmol} / \mathrm{kg}(n=9)]$ in WT and mMCP-4 KO mice, and their respective HR (D and E). Each point corresponds to the mean \pm S.E.M. of the MAP increase. $* P<0.05 ; * * * P<0.001$ vs. WT + vehicle by Student's $t$ test. 

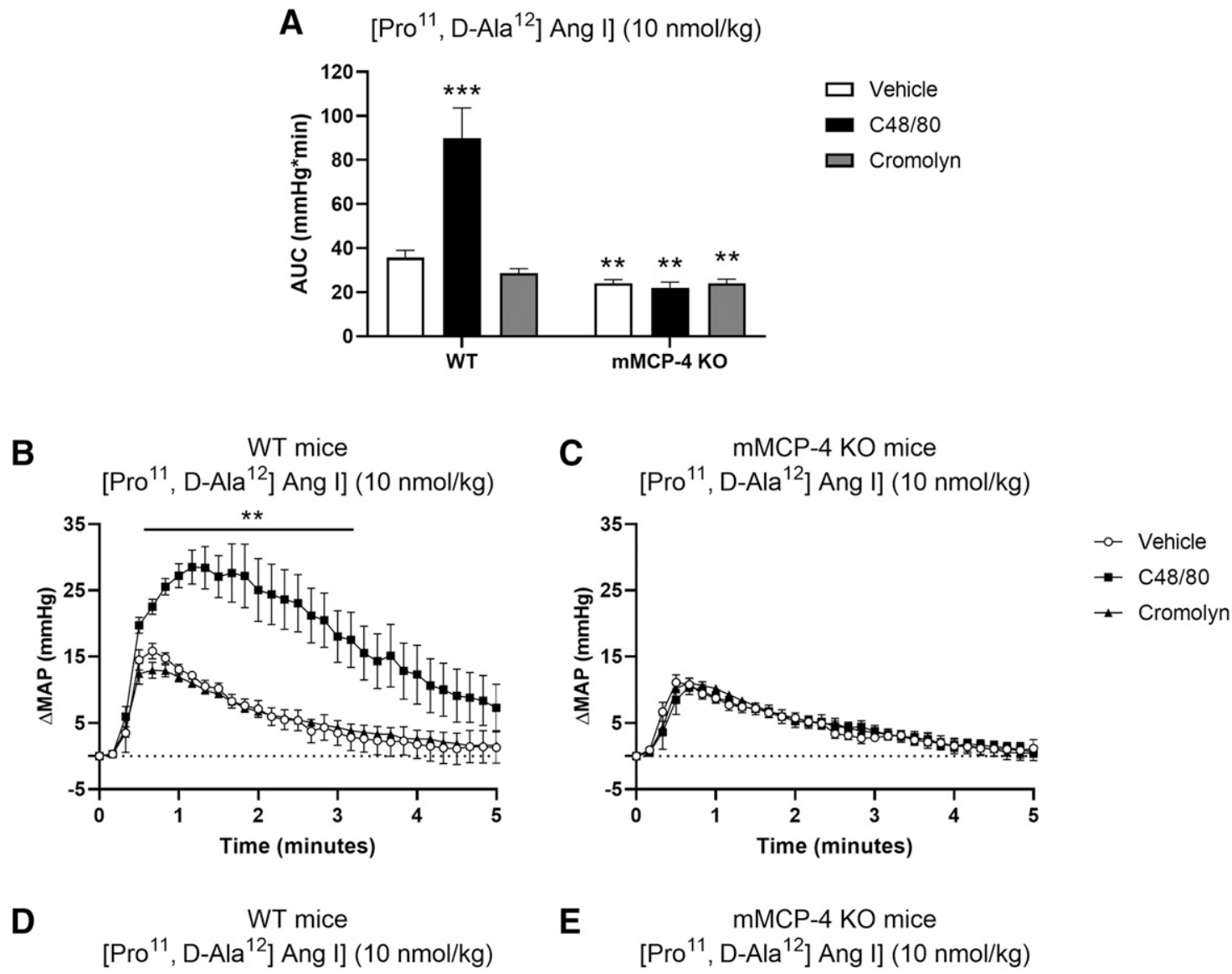

$\mathbf{E}$
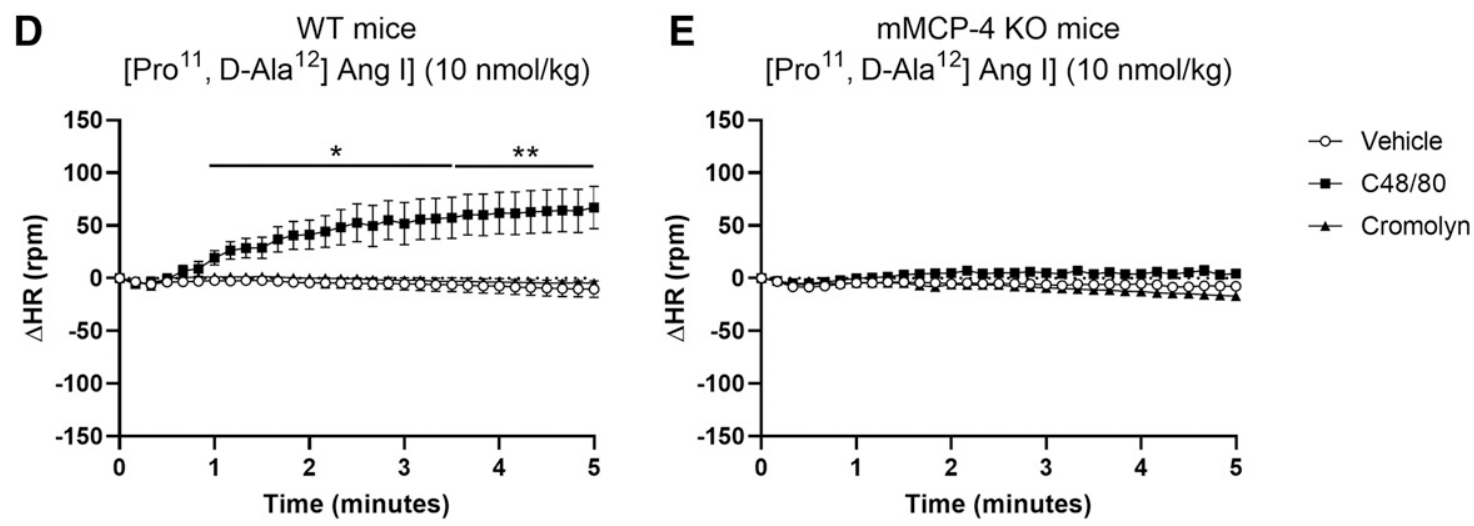

Fig. 6. (A) Time course [area under the curve (AUC)] of [Pro ${ }^{11}$, D-Ala $\left.{ }^{12}\right]$ Ang I (10 nmol/kg) in WT or mMCP-4 KO mice pretreated with either vehicle, C48/80 or cromolyn; maximal variation in MAP in response to intravenous administration of $\left[\right.$ Pro $\left.^{11}, \mathrm{D}_{-A l a}{ }^{12}\right]$ Ang I in (B) WT and (C) mMCP-4 KO mice, and their respective $\mathrm{HR}$ (D and E). Each point and bar correspond to the mean \pm S.E.M. of 7 to 8 separate experiments. ${ }^{*} P<0.05 ; * * P<0.01$ vs. WT + vehicle by one-way ANOVA with Dunnett's multiple comparison test (A) and Student's $t$ test (B and D).

properties of Ang I, suggesting an important role of mast cell stability in the ECE-independent cardiovascular properties of big ET-1 but not in the ACE-independent pressor responses to Ang I in vivo.

NEP is required to produce ET-1 from chymase-generated ET-1 (1-31) in vivo (Fecteau et al., 2005). Data reported prior to the present study suggests that repression of mMCP-4 in mice does not affect endothelin receptors or NEP expression in the mouse cardiovascular system (Houde et al., 2013). We herein show that ET-1 (1-31) and ET-1 administration induce similar hemodynamic responses regardless of whether mast cells are activated or stabilized, thus illustrating that secreted mMCP-4 plays no significant role in the cardiovascular response to these two endothelin metabolites in the mouse model.
The present study also argues in favor of a significant impact of mast cell stability in the production of ET-1 (1-31) in vitro. The loss of big ET-1 conversion capacity in mast cells derived from mMCP-4 KO mice is correlated with the absence of chymase-like hydrolysis in the in vitro series of experiments using the fluorogenic substrate Suc-Leu-Leu-Val-Tyr-AMC. These results show that induction of mast cell degranulation by C48/80 leads to the release of chymase, whereas cromolyn stabilizes the mMCP-4 content within secretory granules.

Borland et al. (1998) reported that, in the human saphenous vein, chymase is located within the adventitia (outer layer of the vessel) and is colocated with mast cell populations, whereas ACE is mainly found in the vascular endothelium. Borland et al. (1998) also suggested that circulating Ang I would be more accessible to ACE than to chymase. In addition, 
circulating chymase is rapidly and irreversibly inhibited by plasma proteins such as alpha-macroglobulins and alpha-1antichymotrypsin, which limits the contribution of the mast cell serine protease in the production of vascular Ang II (Walter et al., 1996). Tissue chymase thus is likely to be of greater importance in the functional effects of Ang II on the smooth muscle cells of blood vessel walls than in the systemic circulation (Borland et al., 1998). Moreover, we previously reported no differences in the pressor responses to Ang I in nonanesthetized WT and mMCP-4 KO mice (Semaan et al., 2015). In concordance with those results, we show in the present study that modulation of mast cell degranulation does not impact the vasopressor responses to exogenous Ang I in vivo, suggesting that chymase may not be as biologically relevant for the Ang II precursor as for big ET-1 hydrolysis in the murine systemic circulation. Given the abundance of angiotensin-converting enzyme in the mouse in vivo (Balcells et al., 1997), it is therefore unlikely that chymase is involved in the production of vascular Ang II under physiologic or pathologic conditions in mice.

In contrast, the present study suggests that chymase modulates the cardiovascular responses to the ACE-resistant analog, $\left[\mathrm{Pro}^{11}\right.$, D-Ala $\left.{ }^{12}\right]$ Ang I (Li et al., 2004), in the mouse model. Using ACE inhibitors (captopril and enalapril) as well as a general inhibitor of chymotrypsin-like enzymes (chymostatin), Borland et al. (1998) reported a partial inhibition of the contractile properties of Ang I in human saphenous veins, suggesting the existence of both ACE- and chymaseindependent pathways in the generation of Ang II. However, since several additional enzymes such as trypsin, chymotrypsin, tonin, cathepsin G, and kallikrein can also generate Ang II from Ang I in vitro (Becari et al., 2011), the contribution of these enzymes in the cardiovascular responses to Ang I remains to be investigated in vivo. Interestingly, the present study also reports the sensitivity of the ACE-resistant Ang I analog ([Pro $\left.{ }^{11}, \mathrm{D}^{-\mathrm{Ala}^{12}}\right]$ Ang I) to mast cell degranulation. Specifically, $\left[\mathrm{Pro}^{11}, \mathrm{D}-\mathrm{Ala}^{12}\right]$ Ang I requires mMCP-4 for its optimal vasoactive responses and is susceptible to mast cell degranulation in the mouse model in vivo. Notably, the finding that cromolyn did not reduce the response to the same analog in contrast to that of big ET-1 suggests that $\left[\mathrm{Pro}^{11}, \mathrm{D}^{1} \mathrm{Ala}^{12}\right]$ Ang I is cleaved by interstitially located active mMCP-4 (Takai et al., 2010) rather than by the same enzyme stored in mast cells.

Baroreceptors are activated by changes in blood pressure, resulting in variations in cardiac chronotropism/inotropism and systemic vascular resistance ((Guo et al., 1982); Knape and van Zwieten, 1988). In the present study, no effects on the heart rate were observed even at the highest doses tested of the two endogenous vasopressors big ET-1 or Ang I. In contrast, a submaximal dose $\left(10^{-8} \mathrm{~mol} / \mathrm{kg}\right)$ of $\left[\mathrm{Pro}^{11}, \mathrm{D}-\mathrm{Ala}^{12}\right]$ Ang I induced significant increases in HR only in C48/80 pretreated mice, caused perhaps by higher plasma levels of chymase-produced Ang II and subsequent activation of the baroreceptor function through the Ang II type 1 receptor (Wong et al., 1993; (Matsumura et al., 1999)).

A significant role for mMCP-4 in a mouse model of experimental autoimmune encephalomyelitis was also recently reported by our laboratory (Desbiens et al., 2016, 2019). Those studies showed an increase in the mMCP4-dependent production of ET-1 in the periphery and the central nervous system. More recently, Pinke et al. (2020) reported that mast cell stabilization with ketotifen lowers disease prevalence and severity as well as the expression of chymase and carboxypeptidase A in mice, thus supporting a potentially therapeutic indication for mast cell stabilizers in multiple sclerosis (Pinke et al., 2020). Deleterious roles for mast cell-derived chymase have also been shown in experimental models of cardiac infarct, ischemia/reperfusion, and atherosclerosis (Jin et al., 2003; Tejada et al., 2016; Houde et al., 2018). Finally, patients with myocardial infarction show increased levels of plasmatic and cardiac ET-1 (1-31) and chymase activity in the same organ (Oka et al., 2014). Whether increased chymase production prompted by mast cells activation under inflammatory conditions is correlated with enhanced production of ET-1 levels in cardiovascular diseases, however, remains to be investigated.

Vascular or autoimmune diseases in which inflammatory processes associated with mast cell activation have been documented (Hermans et al., 2019; Kempuraj et al., 2020) and, interestingly, also recently reported in coronavirus disease 2019 patients with hyperinflammation (Afrin et al., 2020). Furthermore, Ahmad et al. (2019) suggested that stabilizing mast cells could prevent cardiac remodeling since chymase has a high affinity for the human Ang I peptide, in vitro. Agents enhancing mast cell stability may thus have beneficiary effects by reducing the deleterious contribution of chymase, Ang II, and as shown in this study, ET-1, in proinflammatory cardiac and vascular disorders.

\section{Acknowledgments}

The authors thank Kévin Ly (PhenoSwitch Bioscience Inc.) for the mass spectrometry experiments, Dr Jean-Bernard Denault (Université de Sherbrooke) for the spectrofluorometry experiments, and Roxane Desjardins for the recombinant mMCP-4. TY-51469 was provided by Toa Eiyo Ltd.

\section{Authorship Contributions}

Participated in research design: Vincent, Lapointe, D'OrléansJuste.

Conducted experiments: Vincent, Lo, Gagnon.

Performed data analysis: Vincent, Gagnon.

Contributed new reagents or analytic tools: Pejler, Takai, Day, D'Orléans-Juste.

Wrote or contributed to the writing of the manuscript: Vincent, Lapointe, Pejler, D’Orléans-Juste.

\section{References}

Afrin LB, Weinstock LB, and Molderings GJ (2020) Covid-19 hyperinflammation and post-Covid-19 illness may be rooted in mast cell activation syndrome. Int $J$ Infect Dis 100:327-332.

Ahmad S, Wright KN, Sun X, Groban L, and Ferrario CM (2019) Mast cell peptidases (carboxypeptidase A and chymase)-mediated hydrolysis of human angiotensin-(112) substrate. Biochem Biophys Res Commun 518:651-656.

Akasu M, Urata H, Kinoshita A, Sasaguri M, Ideishi M, and Arakawa K (1998) Differences in tissue angiotensin II-forming pathways by species and organs in vitro. Hypertension 32:514-520.

Balcells E, Meng QC, Johnson WH Jr, Oparil S, and Dell'Italia LJ (1997) Angiotensin II formation from ACE and chymase in human and animal hearts: methods and species considerations. Am J Physiol 273:H1769-H1774.

Becari C, Oliveira EB, and Salgado MCO (2011) Alternative pathways for angiotensin II generation in the cardiovascular system. Braz J Med Biol Res 44:914-919. Blank U (2011) The mechanisms of exocytosis in mast cells. Adv Exp Med Biol 716: $107-122$.

Borland JA, Chester AH, Morrison KA, and Yacoub MH (1998) Alternative pathways of angiotensin II production in the human saphenous vein. $\mathrm{Br} J$ Pharmacol 125: $423-428$.

Company C, Piqueras L, Naim Abu Nabah Y, Escudero P, Blanes JI, Jose PJ, Morcillo EJ, and Sanz M-J (2011) Contributions of ACE and mast cell chymase to endogenous angiotensin II generation and leucocyte recruitment in vivo. Cardiovasc Res 92:48-56. 
Davenport AP, Hyndman KA, Dhaun N, Southan C, Kohan DE, Pollock JS, Pollock DM, Webb DJ, and Maguire JJ (2016) Endothelin. Pharmacol Rev 68:357-418.

Desbiens L, Lapointe C, Gendron L, Gharagozloo M, Vincent L, Pejler G, Gris D, and D'Orléans-Juste P (2019) Experimental autoimmune encephalomyelitis potentiates mouse mast cell protease 4-dependent pressor responses to centrally or systemically administered big endothelin-1. J Pharmacol Exp Ther 370:437-446.

Desbiens L, Lapointe C, Gharagozloo M, Mahmoud S, Pejler G, Gris D, and D'Orléans-Juste P (2016) Significant contribution of mouse mast cell protease 4 in early phases of experimental autoimmune encephalomyelitis. Mediators Inflamm 2016:9797021.

D'Orléans-Juste P, Houde M, Rae GA, Bkaily G, Carrier E, and Simard E (2008) Endothelin-1 (1-31): from chymase-dependent synthesis to cardiovascular pathologies. Vascul Pharmacol 49:51-62.

Fecteau M-H, Honoré J-C, Plante M, Labonté J, Rae GA, and D'Orléans-Juste P (2005) Endothelin-1 (1-31) is an intermediate in the production of endothelin-1 after big endothelin-1 administration in vivo. Hypertension 46:87-92.

Fleming I (2006) Signaling by the angiotensin-converting enzyme. Circ Res 98: 887-896.

Guo G B, Thames M D, and Abboud F M (1982) Differential baroreflex control of heart rate and vascular resistance in rabbits. Relative role of carotid, aortic, and cardiopulmonary baroreceptors. Circ Res 50 (4):554-565, doi: 10.1161/ 01.res.50.4.554 6802513 .

Hermans M, Lennep JRV, van Daele P, and Bot I (2019) Mast cells in cardiovascular disease: from bench to bedside. Int J Mol Sci 20:3395.

Houde M, Jamain M-D, Labonté J, Desbiens L, Pejler G, Gurish M, Takai S, and D'Orléans-Juste P (2013) Pivotal role of mouse mast cell protease 4 in the conversion and pressor properties of Big-endothelin-1. J Pharmacol Exp Ther 346:31-37.

Houde M, Schwertani A, Touil H, Desbiens L, Sarrhini O, Lecomte R, Lepage M, Gagnon H, Takai S, Pejler G, et al. (2018) Mouse mast cell protease 4 deletion protects heart function and survival after permanent myocardial infarction. Front Pharmacol 9:868.

Irman-Florjanc T and Erjavec F (1983) Compound 48/80 and substance P induced release of histamine and serotonin from rat peritoneal mast cells. Agents Actions 13:138-141.

Jin D, Takai S, Yamada M, Sakaguchi M, Kamoshita K, Ishida K, Sukenaga Y, and Miyazaki M (2003) Impact of chymase inhibitor on cardiac function and survival after myocardial infarction. Cardiovasc Res 60:413-420.

Kempuraj D, Ahmed ME, Selvakumar GP, Thangavel R, Raikwar SP, Zaheer SA Iyer SS, Govindarajan R, Nattanmai Chandrasekaran P, Burton C, et al. (2020) Acute traumatic brain injury-induced neuroinflammatory response and neurovascular disorders in the brain. Neurotox Res DOI: 10.1007/s12640-020-00288-9 [published ahead of print].

Knape JTA and van Zwieten PA (1988) Positive chronotropic activity of angiotensin II in the pithed normotensive rat is primarily due to activation of cardiac $\beta$ adrenoceptors. Naunyn Schmiedebergs Arch Pharmacol 338:185-190.

Koide Y, Tatsui A, Hasegawa T, Murakami A, Satoh S, Yamada H, Kazayama S, and Takahashi A (2003) Identification of a stable chymase inhibitor using a pharmacophore-Based database search. Bioorg Med Chem Lett 13:25-29.

Kunori Y, Muroga Y, Iidaka M, Mitsuhashi H, Kamimura T, and Fukamizu A (2005) Species differences in angiotensin II generation and degradation by mast cell chymases. J Recept Signal Transduct Res 25:35-44.

Li M, Liu K, Michalicek J, Angus JA, Hunt JE, Dell'Italia LJ, Feneley MP, Graham RM, and Husain A (2004) Involvement of chymase-mediated angiotensin II generation in blood pressure regulation. $J$ Clin Invest 114:112-120.

Matsumura K, Averill D B, and Ferrario C M (1999) Role of AT1 receptors in area postrema on baroreceptor reflex in spontaneously hypertensive rats. Brain Res 850 (1-2):166-172, doi: 10.1016/s0006-8993(99)02128-9 10629761.

McDonald JE, Padmanabhan N, Petrie MC, Hillier C, Connell JM, and McMurray JJ (2001) Vasoconstrictor effect of the angiotensin-converting enzyme-resistant chymase-specific substrate [Pro(11)(D)-Ala(12)] angiotensin I in human dorsal hand veins: in vivo demonstration of non-ace production of angiotensin II in humans. Circulation 104:1805-1808.

McMahon EG, Palomo MA, Moore WM, McDonald JF, and Stern MK (1991) Phosphoramidon blocks the pressor activity of porcine big endothelin-1-(1-39) in vivo and conversion of big endothelin-1-(1-39) to endothelin-1-(1-21) in vitro. Proc Natl Acad Sci USA 88:703-707.

Moore JE III and James GW III (1953) A simple direct method for absolute basophil leucocyte count. Proc Soc Exp Biol Med 82:601-603.

Nakano A, Kishi F, Minami K, Wakabayashi H, Nakaya Y, and Kido H (1997) Selective conversion of big endothelins to tracheal smooth muscle-constricting 31amino acid-length endothelins by chymase from human mast cells. J Immunol $\mathbf{1 5 9}$ : 1987-1992.

Oka M, Niwa Y, Mawatari K, Hiasa Y, and Nakaya Y (2014) A novel peptide of endothelin family, 31 amino-acid length endothelin in patients with acute myocardial infarction. J Med Invest 61:298-305.

Pejler G, Rönnberg E, Waern I, and Wernersson S (2010) Mast cell proteases: multifaceted regulators of inflammatory disease. Blood 115:4981-4990.

Pinke KH, Zorzella-Pezavento SFG, de Campos Fraga-Silva TF, Mimura LAN, de Oliveira LRC, Ishikawa LLW, Fernandes AAH, Lara VS, and Sartori A (2020) Calming down mast cells with ketotifen: a potential strategy for multiple sclerosis therapy? Neurotherapeutics 17:218-234.

Röhlich P, Anderson P, and Uvnäs B (1971) Electron microscope observations on compounds 48-80-induced degranulation in rat mast cells. Evidence for sequential exocytosis of storage granules. J Cell Biol 51:465-483.

Rossi GP, Sacchetto A, Cesari M, and Pessina AC (1999) Interactions between endothelin-1 and the renin-angiotensin-aldosterone system. Cardiovasc Res 43: 300-307.

Samoszuk M and Corwin MA (2003) Mast cell inhibitor cromolyn increases blood clotting and hypoxia in murine breast cancer. Int $J$ Cancer 107:159-163.

Semaan W, Desbiens L, Houde M, Labonté J, Gagnon H, Yamamoto D, Takai S, Laidlaw T, Bkaily G, Schwertani A, et al. (2015) Chymase inhibitor-sensitive synthesis of endothelin-1 (1-31) by recombinant mouse mast cell protease 4 and human chymase. Biochem Pharmacol 94:91-100.

Simard E, Jin D, Takai S, Miyazaki M, Brochu I, and D'Orléans-Juste P (2009) Chymase-dependent conversion of Big endothelin-1 in the mouse in vivo. $J$ Pharmacol Exp Ther 328:540-548.

Skedinger MC, Augustine NH, Morris EZ, Nielson DW, Zimmerman GA, and Hill HR (1987) Effect of disodium cromoglycate on neutrophil movement and intracellular calcium mobilization. J Allergy Clin Immunol 80:573-577.

Takai S, Jin D, and Miyazaki M (2010) New approaches to blockade of the reninangiotensin-aldosterone system: chymase as an important target to prevent organ damage. J Pharmacol Sci 113:301-309.

Tariq M, Moutaery MA, Elfaki I, Arshaduddin M, and Khan HA (2006) Protective effects of nedocromil sodium and sodium cromoglycate on gastroduodenal ulcers: a comparative study in rats. Inflammopharmacology 14:163-169.

Tchougounova E, Pejler G, and Åbrink M (2003) The chymase, mouse mast cell protease 4 , constitutes the major chymotrypsin-like activity in peritoneum and ear tissue. A role for mouse mast cell protease 4 in thrombin regulation and fibronectin turnover. J Exp Med 198:423-431.

Tejada T, Tan L, Torres RA, Calvert JW, Lambert JP, Zaidi M, Husain M, Berce MD Naib H, Pejler G, et al. (2016) IGF-1 degradation by mouse mast cell protease 4 promotes cell death and adverse cardiac remodeling days after a myocardial infarction. Proc Natl Acad Sci USA 113:6949-6954.

Walter M, Plotnick M, and Schechter NM (1996) Inhibition of human mast cell chymase by secretory leukocyte proteinase inhibitor: enhancement of the interaction by heparin. Arch Biochem Biophys 327:81-88.

Wong J, Chou L, and Reid IA (1993) Role of AT1 receptors in the resetting of the baroreflex control of heart rate by angiotensin II in the rabbit. $J$ Clin Invest 91: 1516-1520.

Xu D, Emoto N, Giaid A, Slaughter C, Kaw S, deWit D, and Yanagisawa M (1994) ECE-1: a membrane-bound metalloprotease that catalyzes the proteolytic activation of big endothelin-1. Cell 78:473-485.

Address correspondence to: Pedro D'Orléans-Juste, Department of Pharmacology and Physiology, Université de Sherbrooke, 3001, 12e Ave. Nord, Sherbrooke, Quebec, Canada J1H 5N4. E-mail: labpdj@usherbrooke.ca 